\title{
Caracterização dos parâmetros circulatórios da artéria supratesticular em touros através da ultrassonografia Doppler
}

Flavio Antonio Barca Junior ${ }^{[a]}$, Celso Koetz Junior ${ }^{[a]}$, Gabriel Ribas Pereira ${ }^{[b]}$, Silvio Renato Oliveira Menegassi[b], Fabio Morotti ${ }^{[c]}$, Júlio Otávio Jardim Barcellos ${ }^{[b]}$, Luis Afonso Marques Claus ${ }^{[c]}$, Emilly Pitman de Castro ${ }^{[c]}$, Anne Kemmer Souza ${ }^{[c]}$, Marcelo Marcondes Seneda $a^{[c]}$

\footnotetext{
[a] Universidade Norte do Paraná (UNOPAR), Arapongas, PR, Brasil

${ }^{[b]}$ Núcleo de Estudos em Sistemas de Produção de Bovinos de Corte e Cadeia Produtiva, Universidade Federal do Rio Grande do Sul (UFRGS), Porto Alegre, RS, Brasil

[c] Universidade Estadual de Londrina (UEL), Londrina, PR, Brasil
}

*Autor correspondente

e-mail: marcelo.seneda@gmail.com

\section{Resumo}

\begin{abstract}
A hemodinâmica testicular pode contribuir para a melhor compreensão dos mecanismos fisiológicos de termorregulação, nutrição e aporte de oxigênio do testículo, sendo imprescindível valores de referência para isto. 0 presente estudo teve como objetivo caracterizar os parâmetros circulatórios de velocidade média (VM), índice de pulsatilidade (PI) e de resistividade (RI) da artéria testicular em touros, utilizando 344 touros de cinco diferentes raças, avaliadas por meio de análise velocimétrica Doppler. A comparação dos dados foi realizada por ANOVA e estabelecida a correlação linear de Pearson, tendo sido em todos os casos o nível mínimo de significância 5\%. A VM apresentou média geral de 12,14 $\pm 5,61 \mathrm{~cm} / \mathrm{s}$, sendo que houve diferença significativa $(\mathrm{P}<0,05)$ para raça, sendo a maior média verificada para os animais da raça Brangus $(16,28 \pm 5,50 \mathrm{~cm} / \mathrm{s})$ e o menor valor para os animais Nelore $(8,76 \pm 2,65 \mathrm{~cm} / \mathrm{s})$. 0 índice de resistência (RI) teve média geral de $0,41 \pm 0,14$, sendo que houve diferença significativa para as diferentes raças avaliadas $(\mathrm{P}<0,05)$ : o maior valor verificado foi em animais Hereford $(0,44 \pm 0,14)$ e o menor nos Brangus $(0,36 \pm$ $0,11)$. Os valores de PI não apresentaram diferença significativa $(P>0,05)$ e obteve média geral de $0,33 \pm$ 0,16 . A correlação entre PIxRI foi alta e positiva $(0,908)$, e as correlações entre VMxPI $(-0,179)$ e VMxRI $(-0,248)$ foram baixas e negativas. Desta forma pode-se concluir que existe diferença na VM e RI da artéria supra testicular de touros nas diferentes raças avaliadas. Os valores apresentados podem contribuir como parâmetro para futuros estudos e também para o diagnóstico de afecções.
\end{abstract}

